\title{
Rancang Bangun Smart Robot Omni Wheel sebagai Permainan Edukatif dan Interaktif bagi Balita
}

\author{
Muhammad Nur \\ Program Studi Teknik Mekatronika \\ Politeknik Bosowa \\ Makassar, Indonesia \\ muhammadnur@politeknikbosowa.ac.id
}

\author{
Tantri Indrabulan \\ Program Studi Teknik Komputer dan Jaringan \\ Politeknik Negeri Ujung Pandang \\ Makassar, Indonesia \\ tantri.indrabulan3@gmail.com
}

\begin{abstract}
The purpose of this research is to produce a smart robot prototype that is able to attract toddlers' attention so that they can respond in the form of motor movements. The making of smart robots will be adjusted to the needs of toddler stimulation in the form of movement interactions approaching or away from objects so that toddlers are triggered to chase or avoid the robot. Educational games that are designed appropriately for toddlers can improve their motor development. This can occur due to stimulating activities from educational games that can stimulate the toddler's brain. Smart robots are one of the educational game technology products that apply the concept of the industrial revolution 4.0. The smart robot prototype design will use the arduino mega microcontroller. The microcontroller input is obtained from a proximity sensor that is implanted in the robot's body. The essence of the smart robot in this study is a dynamic and very flexible robot movement caused by the use of the omni wheel as a driving wheel.
\end{abstract}

Keywords-educational games; smart robot; omni wheel; microcontroller

\section{PENDAhUluan}

Sumber daya manusia yang unggul, sebagai pelaku dalam pembangunan nasional jangka panjang, dihasilkan dari berbagai upaya pembentukan karakter individu yang dapat dimulai sejak masa kanak-kanak utamanya pada masa balita [1]. Pembentukan karakter bergantung pada pemberian stimulasi terhadap otak sehingga terjadi pertumbuhan dan perkembangan menuju kematangan terkhusus pada fungsi kognitif, afektif dan psikomotor. Menurut Febrina Suci Hati dan Prasetya Lestari, stimulasi yang dilakukan saat periode balita melalui interaksi yang tepat dan latihan fisik yang sesuai akan dapat mengembangkan kinerja motorik secara signifikan. Hal tersebut akan berdampak positif terhadap kemampuan kognitif anak [2]. Dari hasil penelitian yang dilakukan oleh Shubhangna Sharma dan Shipra Nagar diketahui bahwa psikomotor bayi dan anak menjadi lebih baik setelah diberikan berbagai intervensi rangsangan salah satunya berupa mainan [3]. Penelitian tentang stimulasi anak menggunakan mainan juga telah dilakukan dengan menerapkan konsep alat permainan edukatif (APE) yang dinilai mampu mengembangkan kemampuan motorik dan keterampilan anak [4].
Mengikuti perkembangan teknologi yang saat ini telah memasuki era digital dalam revolusi industri 4.0 maka setiap individu dituntut mampu beradaptasi terhadap lingkungan teknologi. Tidak hanya orang dewasa, sejak dini anak-anak telah dipersiapkan agar dapat menghadapi era digital utamanya dari aspek pendidikan. Khusus bagi balita, salah satu bentuk pendidikan tentang teknologi tersebut dapat berupa permainan edukatif yaitu robot. Permainan edukatif dalam bentuk robot bagi balita dituntut agar dapat menarik perhatiannya sekaligus bersifat interaktif dengan kemampuan bergerak ke segala arah yang tentunya akan menjadi daya tarik tersendiri.

Rancangan robot interaktif dapat diadaptasi dari berbagai penelitian salah satunya pada penelitian [5] yang merancang robot penyedot debu dengan dukungan omni wheel. Gerakan robot dikendalikan oleh sensor accelerometer pada smartphone Android melalui komunikasi bluetooth. Penggunaan omni wheel pada robot tersebut memudahkan gerakan ke segala arah secara efisien. Penelitian [6] merancang Robot Micro Ball-Balancing (MBBR) dengan keleluasaan gerak yang sangat tinggi. Modifikasi dilakukan pada desain omni wheel yang terhubung ke bola dengan menempatkannya pada posisi sekitar $20^{\circ}$ hingga $30^{\circ}$ dari arah utara vertikal sehingga mampu meningkatkan kekuatan antara omni wheel dan bola. Selain itu omni wheel diarahkan ke bidang yang saling ortogonal agar dapat meningkatkan efisiensi dan menciptakan gerakan bola yang sangat bebas. Merujuk pada kedua penelitian tersebut disimpulkan bahwa kemampuan untuk bergerak secara bebas sangat dipengaruhi oleh pemilihan jenis roda yang akan digunakan dan menjadi pertimbangan yang cukup penting. Robot yang menggunakan omni wheel akan dapat bergerak ke segala arah secara instan tanpa didahului gerakan memutar [7]. Berdasarkan hal tersebut maka jenis roda yang akan digunakan pada penelitian untuk merancang smart robot sebagai permainan bagi balita yaitu omni wheel. Konsep interaktif dalam penelitian ini didefinisikan dalam bentuk kemampuan balita dalam bergerak mengejar robot atau menghindari robot. Selain berfungsi sebagai media pengenalan teknologi bagi balita, interaksi terhadap smart robot tersebut secara langsung dapat memicu stimulasi bagi perkembangan motoriknya. 
Kemampuan untuk bergerak secara bebas pada omni wheel erat kaitannya dengan jenis platform yang digunakan. Penelitian [8] telah menganalisis dinamika gerakan bebas dan terkendali pada omni wheel secara matematis berdasarkan platform yang digunakan. Penelitian ini mencoba menyederhanakan perhitungan yang cukup rumit untuk menurunkan persamaan gerak. Penelitian tersebut juga mendeskripsikan skema dan parameter dalam persamaan gerak yang memungkinkan untuk digunakan pada kendaraan omni wheel. Termasuk di dalamnya platform segitiga dengan sudut $120^{\circ}$. Masih terkait dengan kemampuan omni wheel berdasarkan platform, penelitian [9] melakukan sebuah pendekatan baru untuk memodelkan dinamika dan desain pengontrolan pada platform seluler omni wheel. Hal tersebut berdasarkan pada tuntutan terhadap dinamika gerakan yang tinggi. Penelitian ini juga menjelaskan kondisi kopling tambahan agar motor listrik dapat bekerja dalam kondisi yang optimal berkaitan dengan kekuatan untuk menghasilkan torsi yang diinginkan. Model platform yang digunakan yaitu omnidirectional dari gabungan 3 buah omni wheel. Serupa dengan kedua penelitian terhadap kemampuan gerak omni wheel, [10] mencoba menerapkan sistem pengontrolan tertanam pada kendaraan omni wheel namun jumlah roda yang digunakan yaitu 4 buah sehingga membentuk platform persegi. Penelitian ini menggunakan Proportional-Integral-Derivative controller (PID) untuk menjaga kestabilan gerakan. Pengujian dilakukan dengan menganalisis gerakan kendaraan terhadap penyimpangan dari titik-titik posisi tujuan. Hasil penelitian menunjukkan bahwa sistem mampu meminimalisir terjadinya penyimpangan arah gerakan.

Tujuan khusus dari perancangan prototipe smart robot pada penelitian ini yaitu untuk memicu interaksi balita terhadap robot sehingga platform yang digunakan sebaiknya sesederhana mungkin tanpa mengurangi kemampuan robot untuk bergerak bebas. Oleh karena itu akan digunakan jenis platform segitiga dengan 3 buah roda jenis omni wheel yang membentuk sudut $120^{\circ}$. Mekanisme kontrol manual tidak akan digunakan karena konsep smart yang diusung, sebagai gantinya digunakan pengontrolan PID terhadap keluaran dari sensor jarak agar robot dapat bergerak secara otomatis.

\section{Metode Penelitian}

Tahapan pertama penelitian yaitu mengkaji literatur sebagai acuan dasar perancangan. Setelah diperoleh konsep perancangan yang matang maka dilanjutkan ke tahapan perencanaan mekanisme yang meliputi struktur dan hardware. Pada tahapan ini dilakukan pemodelan struktur robot utamanya desain penempatan omni wheel pada bodi robot.

Berdasarkan desain awal perancangan ditetapkan bahwa robot akan berbentuk tabung dengan tujuan menyederhanakan bodi dan lebih menonjolkan nyala Light Emitting Diode (LED) sebagai bagian yang akan menarik perhatian. Lingkaran pada dasar tabung akan berlubang bertujuan sebagai tempat penghubung omni wheel ke motor arus searah (DC). Jumlah omni wheel yang digunakan yaitu 3 buah dengan sudut letak masing-masing sebesar $120^{\circ}$. Gambar 1 menunjukkan hasil desain rangka dasar robot serta posisi penempatan omni wheel. lingkaran rangka berdiameter $22 \mathrm{~cm}$ dengan 3 buah celah persegi untuk menempatkan omni wheel yang terhubung pada motor DC.

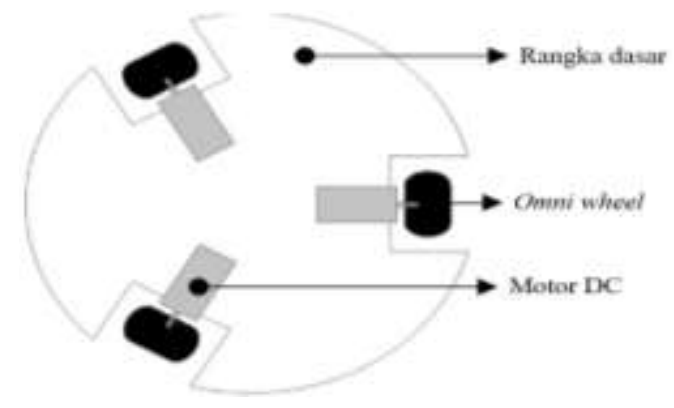

Gambar 1. Desain penempatan omni wheel pada dasar robot

Pada bagian perencanaan hardware telah dilakukan riset awal mengenai pemilihan komponen dan rangkaian yang akan digunakan dalam sistem. Metode yang digunakan ialah trial error terhadap kinerja komponen. Tahapan tersebut dimulai dari perancangan sistem dengan melakukan desain berupa pembuatan minimum sistem menggunakan mikrokontroller arduino mega. Selanjutnya akan dirancang beberapa sistem penunjang yang dilengkapi dengan komponenkomponen antara lain perancangan sensor jarak, pembuatan driver penggerak motor, penggunaan tombol, dan tampilan output Liquid Crystal Display (LCD) serta LED. Sensor jarak berfungsi sebagai input yang akan menjadi acuan respon pergerakan robot. Respon gerakan terbagi ke dalam 2 mode yaitu mode menjauhi objek dan mode mendekati objek. Keduanya dapat diatur menggunakan tombol sesuai dengan kebutuhan. Hubungan antara komponen dalam sistem dapat dilihat pada gambar 2 .

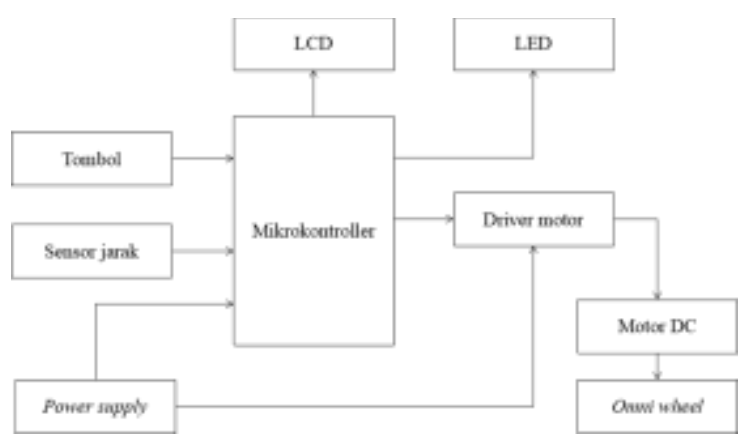

Gambar 2. Blok diagram perancangan sistem

Tahapan perancangan mekanik merupakan proses perancangan bodi dan perakitan robot. Bodi dibentuk menggunakan printer 3 dimensi (3D) sesuai dengan desain struktur yang telah dirancang yaitu memiliki tinggi $10 \mathrm{~cm}$. Selanjutnya seluruh perangkat sistem dan komponen akan dirakit menjadi satu kesatuan. Ketika robot telah selesai dirakit maka berikutnya dilakukan tahapan pemrograman. Tahapan tersebut merupakan kunci dari perancangan smart robot. Proses pemrograman akan mengintegrasikan seluruh komponen masukan ke mikrokontroller melalui 


\section{Rancang Bangun Smart Robot Omni Wheel sebagai Permainan Edukatif dan Interaktif bagi Balita}

software kemudian diubah menjadi output baik itu berupa tampilan LCD, nyala LED, maupun pergerakan omni wheel.

Parameter jarak yang digunakan untuk respon gerakan robot yaitu jika jarak lebih kecil dari $30 \mathrm{~cm}$ maka objek akan bergerak menjauh dan objek akan bergerak mendekat jika jaraknya lebih besar dari $30 \mathrm{~cm}$ dan lebih kecil dari $50 \mathrm{~cm}$. Selain itu robot juga dilengkapi dengan mode berputar di tempat jika objek berada pada jarak lebih dari $50 \mathrm{~cm}$. Mode tersebut ditambahkan sebagai upaya untuk mencari objek terdekat yang sekaligus dapat menarik perhatian balita. Parameter jarak yang digunakan bersifat fleksibel dan dapat diubah pada tombol pengaturan. Hubungan antara jarak objek ke robot $\left(s_{o}\right)$, parameter jarak minimum $\left(s_{\min }\right)$ dan parameter jarak maksimum $\left(s_{\max }\right)$ terhadap mode pergerakan dapat dinyatakan sebagai berikut.

$$
\text { mode menjauh }=\left(s_{o}\right) \leq\left(s_{\min }\right)
$$

$$
\begin{aligned}
& \text { mode mendekat }=\left(s_{\min }\right)<\left(s_{o}\right) \leq \\
& \left(s_{\max }\right) \ldots \ldots(2) \\
& \quad \text { mode berputar }=\left(s_{o}\right)>\left(s_{\max }\right)
\end{aligned}
$$
(3)

Parameter jarak tersebut dapat disesuaikan dengan karakteristik balita dalam melakukan gerakan.

\section{HASIL DAN PEMBAHASAN}

Penelitian yang telah dilakukan ini menghasilkan sebuah prototipe smart robot yang dilengkapi dengan 3 buah omni wheel sebagai roda penggerak. Berikut ini merupakan tampilan prototipe smart robot tampak dalam.

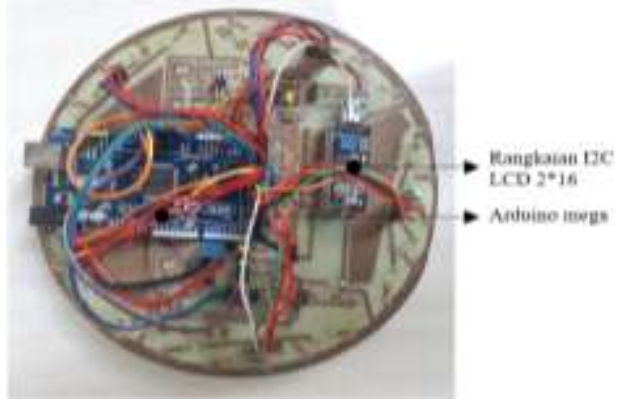

(a)

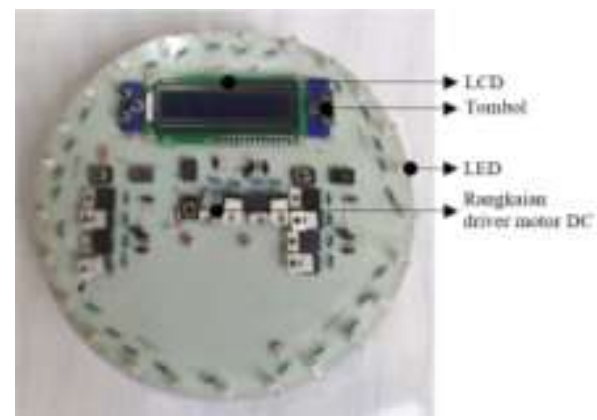

(b)

Gambar 3. Rangkaian dalam prototipe pada penampang bawah (a) dan atas (b)
Gambar 3 menunjukkan sebuah rangkaian Printed Circuit Board (PCB) 1 layer dari sudut penampang bawah dan atas. Board tersebut terdiri dari hasil rancangan minimum sistem menggunakan mikrokontroller arduino mega dan rangkaian sistem penunjang antara lain hasil rancangan sensor jarak, driver penggerak motor, 6 buah tombol untuk pengaturan, output LCD ukuran 16x2 dan sebanyak 25 buah LED. Sedangkan untuk tampilan luar bodi robot dapat dilihat pada gambar berikut.

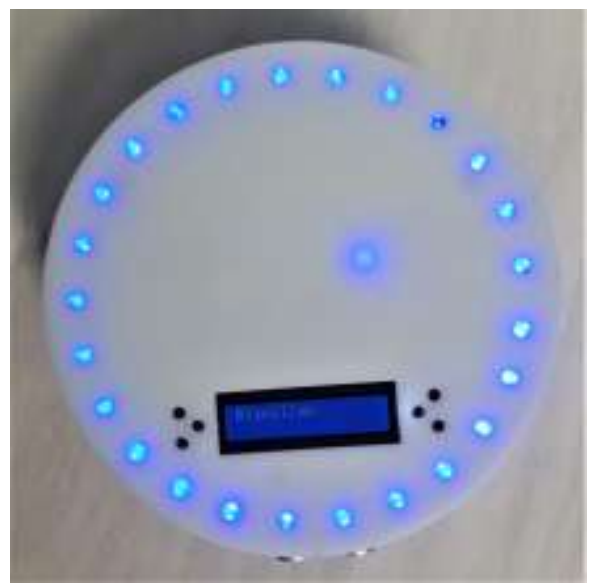

(a)

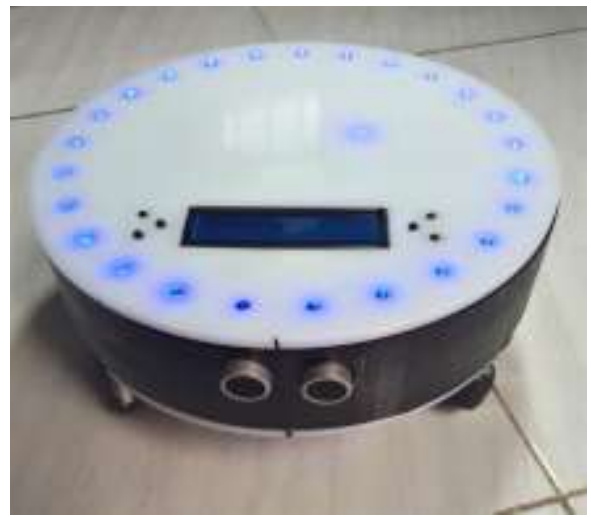

(b)

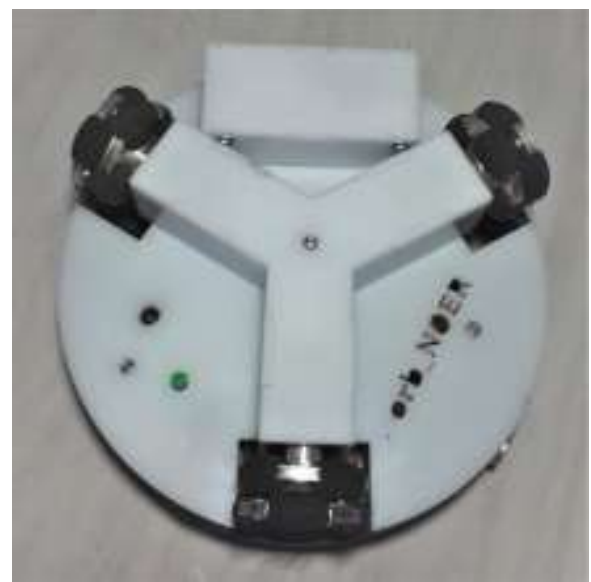

(c)

Gambar 4. Tampilan bodi luar prototipe robot tampak atas (a), samping (b) dan bawah (c) 
Dari gambar 4(b) terlihat bahwa 1 buah sensor jarak di tempatkan pada satu sisi saja. Berdasarkan hal tersebut maka secara teoritis robot hanya dapat bergerak jika posisi objek tepat di depannya saja atau dengan kata lain hanya untuk satu sudut tertentu. Untuk membuktikan hal tersebut maka dilakukan pengujian respon robot terhadap posisi objek. Mekanisme pengujian yaitu dengan menempatkan seseorang (duduk) pada jarak $50 \mathrm{~cm}$ dari robot kemudian posisi sensor jarak dengan orang tersebut akan membentuk sudut-sudut pengujian tertentu sehingga mewakili keseluruhan posisi (sudut $360^{\circ}$ ). Hasil pengujian disajikan pada tabel berikut.

Tabel 1. Respon robot terhadap posisi objek

\begin{tabular}{|c|c|}
\hline $\begin{array}{c}\text { Posisi objek } \\
\text { dalam derajat }\end{array}$ & Respon gerakan \\
\hline 0 & Bergerak \\
\hline 45 & Bergerak \\
\hline 90 & Bergerak \\
\hline 135 & Bergerak \\
\hline 180 & Bergerak \\
\hline 225 & Bergerak \\
\hline 270 & Bergerak \\
\hline 315 & Bergerak \\
\hline
\end{tabular}

Dari tabel 1 diketahui bahwa robot mampu memberikan respon gerakan meskipun objek tidak tepat berada di depan sensor jarak. Hal tersebut dapat terjadi sebab adanya modifikasi pencarian objek saat mode berputar sehingga robot tetap mampu memberikan respon gerakan di sudut manapun objek berada. Sedangkan untuk lebih fokus pada arah gerakan robot maka dilakukan pengujian dengan menempatkan objek tepat dihadapan sensor jarak pada posisi jarak tertentu. Hasil pengujian arah gerakan robot tersebut dapat dilihat pada tabel 2 berikut.

Tabel 2. Arah gerakan robot terhadap jarak objek

\begin{tabular}{|c|c|}
\hline Jarak objek (cm) & Arah gerakan \\
\hline 10 & Menjauh \\
\hline 20 & Menjauh \\
\hline 30 & Menjauh \\
\hline 40 & Mendekat \\
\hline 50 & Mendekat \\
\hline 60 & Berputar \\
\hline$>60$ & Berputar \\
\hline
\end{tabular}

Pergerakan robot tampak lebih dinamis di berbagai sudut dengan adanya 3 buah omni wheel sebagai roda penggerak. pergerakan tersebut tampak dari respon yang diberikan ketika diuji cobakan langsung kepada balita dengan menunjukkan hasil yang baik, terlihat dari antusiasme balita pada ekspresi dan gerakannya. Hal tersebut juga didukung oleh adanya nyala lampu LED yang berkedap-kedip dan menyala bergantian sebagai daya tarik tambahan. Agar memudahkan balita memahami permainan smart robot ini dibutuhkan interaksi verbal dari orang dewasa untuk membantu mengarahkan cara memberikan respon yang sesuai.

\section{KESIMPULAN}

Prototipe smart robot yang dirancang menggunakan 3 buah omni wheel menunjukkan respon gerakan dimanapun posisi objek baik dari sudut maupun jaraknya. Mode pergerakan robot berputar, mendekati dan menjauhi objek merupakan hasil rekayasa agar dapat menarik perhatian yang dapat disesuaikan dengan karakteristik objek balita. Dari sisi penampakan, desain yang unik dan kombinasi warna LED mampu menarik perhatian balita namun untuk lebih meningkatkan interaksi maka pada penelitian selanjutnya disarankan untuk menambahkan perangkat audio.

\section{UCAPAN TERIMA KASIH}

Penelitian ini dapat terlaksana dengan adanya bantuan pendanaan penelitian dari Kementerian Riset dan Teknologi/Badan Riset dan Inovasi Nasional, Deputi Bidang Penguatan Riset dan Pengembangan.

\section{DAFTAR PUSTAKA}

[1] Mulyati, "Psikologi Belajar." Yogyakarta: Andi Offset, Hal, 2005.

[2] F. S. Hati and P. Lestari, "Pengaruh Pemberian Stimulasi pada Perkembangan Anak Usia 12-36 Bulan di Kecamatan Sedayu, Bantul," J. Ners dan Kebidanan Indones., vol. 4, no. 1, p. 44, 2016.

[3] S. Sharma and S. Nagar, "Influence of home environment on psychomotor development of infants in Kangra district of Himachal Pradesh," J. Soc. Sci., vol. 21, no. 3, pp. 225-229, 2009.

[4] N. M. AH, "Penggunaan Alat Permainan Edukatif dalam Menstimulasi Perkembangan Fisik-Motorik Anak Usia Dini," SELING J. Progr. Stud. PGRA, vol. 4, no. 2, pp. 125-138, 2018.

[5] I. Suwanda, "Rancang Bangun Robot Omni Wheel Penyedot Debu Menggunakan Sensor Accelerometer Berbasis Mikrokontroler ATMega16," J. Tek. Elektro Univ. Tanjungpura, vol. 2, no. 1, 2014.

[6] D. Yang, E. Sihite, J. M. Friesen, and T. Bewley, "Design and control of a micro ball-balancing robot (MBBR) with orthogonal midlatitude omniwheel placement," in 2015 IEEE/RSJ International Conference on Intelligent Robots and Systems (IROS), 2015, pp. 4098-4104.

[7] J. J. Parmar and C. V Savant, "Selection of wheels in robotics," Int J Sci Eng Res, vol. 5, no. 10, pp. 339-343, 2014.

[8] A. V Borisov, A. A. Kilin, and I. S. Mamaev, "Dynamics and control of an omniwheel vehicle," Regul. Chaotic Dyn., vol. 20, no. 2, pp. 153-172, 2015.

[9] Z. Gong and U. Konigorski, "Dynamic modeling and controller design of an omniwheel mobile platform by differential parameterization," in 2016 European Control Conference (ECC), 2016, pp. 1532-1537.

[10] A. Bramanta, A. Virgono, and R. E. Saputra, "Control system implementation and analysis for omniwheel vehicle," in 2017 International Conference on Control, Electronics, Renewable Energy and Communications (ICCREC), 2017, pp. 265-270. 